\section{Kidney \\ Blood Pressure Research}

Kidney Blood Press Res 2019; $\square\left[\begin{array}{ll}D^{2} \\ \text { पा }\end{array}\right.$

DOI: $10.1159 / 000498874$

Published online: 22 February 2019

Accepted: 5 February 2019

This article is licensed under the Creative Commons Attribution-NonCommercial-NoDerivatives 4.0 InternaThis article is licensed under the Creative Commons Attribution-NonCommercial-NoDerivatives 4.0 Interna-
tional License (CC BY-NC-ND) (http://www.karger.com/Services/OpenAccessLicense). Usage and distribution for commercial purposes as well as any distribution of modified material requires written permission.

Research Article

\title{
Crescents and Global Glomerulosclerosis in Chinese IgA Nephropathy Patients: A Five- Year Follow-Up
}

\author{
Wei Penga,b Yi Tang ${ }^{\mathrm{a}} \quad$ Li Tan $^{\mathrm{a}} \quad$ Wei Qin ${ }^{\mathrm{a}}$ \\ aDivision of Nephrology, West China Hospital, Sichuan University, Chengdu, bDivision of Nephrology, \\ The first hospital of Fuzhou city, Fujian Medical University, Fuzhou, China
}

\section{Key Words}

$\lg$ A nephropathy $・$ Crescent $•$ Global glomerulosclerosis $•$ Renal outcome

\begin{abstract}
Background/Aims: This study aims to evaluate the clinical significance of crescent and global glomerulosclerosis formation on renal outcome in patients with IgA nephropathy (IgAN). Methods: Biopsy-proven primary IgAN patients from West China Hospital of Sichuan University were studied retrospectively between 2008 and 2015. Clinicopathological features and treatment modalities were recorded. The patients were divided into several groups on the basis of cellular and/or fibrocellular crescents scores and global glomerulosclerosis scores. Crescent (C) was scored according to the updated Oxford classification (C0/C1/C2). Global glomerulosclerosis $(\mathrm{G})$ was scored according to the frequency of global glomerulosclerosis: G0 ( $\leq 25 \%$ of glomeruli), G1 ( $26-50 \%$ of glomeruli), and G2 ( $>50 \%$ of glomeruli). The primary endpoint was defined as a $50 \%$ reduction in renal function or end stage renal disease. Patients were followed up for at least 12 months, or shorter if they reached study endpoints. 1328 patients with IgAN were recruited. Mean follow-up time was $46.1 \pm 23.6$ months. The percentage of patients with C1 and C2 was $19.3 \%$ and $5.9 \%$ respectively. Higher crescent scores was associated with lower estimated glomerular filtration rates (eGFR), decreased serum albumin levels, increased amounts of urine protein, higher serum creatinine, as well as greater proportions of $\mathrm{M} 1$ and E1. The percentage of patients with G0, G1 and G2 was $70.5 \%, 20.7 \%$ and $8.8 \%$, respectively. Elevated glomerulosclerosis scores were associated with lower eGFR levels, increased amounts of urine protein, higher levels of serum creatinine, higher incidences of arterial hypertension, as well as greater proportions of M1. There was a significantly higher proportion of T1/2 in patients with G2. In a multivariate model, crescent and global glomerulosclerosis were identified as independent predictors of decreased renal survival. Conclusion: Global glomerulosclerosis and crescents, as detected in renal biopsies, are strong predictors of long-term renal outcome of IgAN.
\end{abstract}

W. Peng and $Y$. Tang contributed equally to this work.

\begin{tabular}{ll}
\hline Dr Wei Qin & Department of Nephrology, West China Hospital, Sichuan University \\
37th Guoxuexiang Road, Chengdu 610041 (China)
\end{tabular}

Tel. +86-28-85422338, E-Mail ddqstrike@163.com 


\section{Kidney Blood Pressure Research}

\section{Introduction}

Immunoglobulin A nephropathy (IgAN), the most common form of glomerulonephritis, is characterized by the accumulation of IgA immune complex deposits in the mesangium of the kidney [1]. The Oxford classification of IgAN has been widely adopted since 2009, which includes several definitive histological features: mesangial hypercellularity (M), endocapillary proliferation (E), segmental sclerosis or adhesion (S) and tubular atrophy/interstitial fibrosis (T) [2]. Validation studies show a correlation between the Oxford classification and renal outcomes [3]. Considering that glomeruli crescents are highly associated with poor renal outcome [4], cellular and/or fibrocellular crescents (C) were include in the updated Oxford classification of IgAN[5]. It is well known that IgAN is a chronic progressive kidney disease that harbors complex clinical manifestations, and $20-40 \%$ of patients will develop end-stage renal disease (ESRD) within 10-20 years [6]. It is thought that global glomerulosclerosis, characteristic lesion of chronic pathological changes, may be a prognostic indicator of poor renal outcome of kidney disease. Therefore, this study was performed to clarify the clinical significance of crescents and global glomerulosclerosis formation on the renal outcome in IgAN patients.

\section{Materials and Methods}

\section{Patients}

Adult IgAN patients (age > 14 years), verified via renal biopsy, were retrospectively enrolled in between December 2008 and July 2015 from West China Hospital of Sichuan University. Patients with secondary causes of mesangial IgA deposits (including but not limited to Henoch-Schönlein purpura, rheumatology disease, and liver disease) and those with insufficient clinical and pathologic data (renal biopsies less than 8 glomeruli) were excluded from this study. Patients were followed up for at least 12 months or until studydefined endpoints were reached. This study complies with the principles of the Helsinki Declaration and was approved by The Ethics Committee of West China Hospital of Sichuan University. Written informed consent was collected from all patients prior to treatment.

\section{Clinical data}

Demographics (gender, ethnicity, age) and clinical data (blood pressure (BP), serum creatinine, albumin, estimated glomerular filtration rate (eGFR), $24 \mathrm{~h}$ urine protein, and urine red blood cell counts) were collected. Hypertension was defined as BP $>140 / 90 \mathrm{mmHg}$ or requiring the use of antihypertensive agents. eGFR levels were calculated using the Chronic Kidney Disease Epidemiology Collaboration (CKDEPI) equation. Treatment modalities were recorded. Patients received optimized supportive care with full dose angiotensin-converting-enzyme inhibitor (ACEi) or angiotensin receptor blockers (ARB) to achieve target blood pressure (BP < 140/90mmHg). Corticosteroids $(0.5-1 \mathrm{mg} / \mathrm{kg}$ Prednisone daily, tapering down within 6 - 8 months) and immunosuppressant therapy (Cyclophosphamide $2 \mathrm{mg} / \mathrm{kg}$ daily for 3 months, or Mycophenolate Mofetil 1-2 g daily for 6-8 months) were used based on pathological and clinical severity.

\section{Renal pathology data}

Renal biopsy samples from all patients were reviewed by a pathologist and a nephrologist. The updated Oxford Classification (MEST-C) was used in this study (mesangial hypercellularity (M0/M1, <or equal to $>50 \%$ of glomeruli with $>4$ mesangial cells/area); endocapillary hypercellularity (E0/E1, present/absent); segmental glomerulosclerosis (S0/S1, present/absent); tubular atrophy/interstitial fibrosis (T0/T1/T2, $<25 \%, 25-50 \%,>50 \%$ ] [2], and cellular or fibrocellular crescents (C0/C1/C2, no crescents/crescent in a least 1 glomerulus/crescents in at least $25 \%$ of glomeruli) [5]. A crescent was defined as an extracapillary lesion of any size containing more than two cell layers. A cellular crescent was defined by $>50 \%$ of the lesion occupied by cells, and a fibrocellular crescent was defined by $<50 \%$ of the lesion occupied by cells 


\section{Kidney \\ Blood Pressure Research}

Peng et al.: Crescents and Global Glomerulosclerosis in IgA Nephropathy

and $<90 \%$ occupied by matrix. Fibrous crescents (composed of $>90 \%$ matrix) were not taken into account [7]. Global glomerulosclerosis was defined as hyaline deposition or scarring lesion occurring in more than $50 \%$ of any one glomerulus. Global glomerulosclerosis (G) was scored according to the percentage of global glomerulosclerosis: G0 ( $\leq 25 \%$ of glomeruli), G1 (26-50\% of glomeruli), and G2 ( $>50 \%$ of glomeruli).

\section{Outcomes}

Responses to therapy included complete remission (CR), partial remission (PR), no response (NR), and ESRD. CR was defined as urinary protein excretion $<0.5 \mathrm{~g} / 24$ hand eGFR decrease $<10 \%$ of baseline measurements. PR was defined as a decrease in proteinuria $>50 \%$ of baseline and eGFR decrease $<10 \%$ of baseline. NR was defined as a decrease in proteinuria $<50 \%$ of baseline, and decrease of eGFR $>10 \%$ of baseline. Responses to therapy were determined at 6-8 months after the initiation of treatment. ESRD was defined as eGFR $<15 \mathrm{~mL} / \mathrm{min} / 1.73 \mathrm{~m}^{2}$ or need renal replacement treatment. The primary endpoint was a combination of a $50 \%$ decline in eGFR and/or ESRD.

\section{Statistical analysis}

SPSS 22.0 software (SPSS, Chicago, IL, USA) was used for statistical analysis. Categorical data was described with percentages and analyzed using Chi-square tests. Continuous variables were expressed as mean \pm SD or median (first-third interquartile range), and analyzed with ANOVA, Student's t-test or nonparametric Mann-Whitney $U$ test. Survival analysis was performed using log-rank test and Cox regression model. Results were expressed as hazard ratios (HR) with 95\% confidence intervals (CI). Statistical significance was considered if $\mathrm{P}<0.05$. Five year renal survival was predicted using the nearest neighbor estimation method for censored survival data [8]. Prediction accuracy was measured using receiver operating characteristic (ROC) curves and area under ROC curves (AUCs).

\section{Results}

Clinicopathological characteristics

1328 IgAN patients (45.6\% male and $54.4 \%$ female) were recruited. The mean age was $34.2 \pm 11.2$ years. The mean follow-up time was 46.1 \pm 23.6 months. During follow-up, the majority of patients received renin-angiotensin system inhibitors (RASi), and 60.5\% received immunosuppressant. 221 (16.6\%) patients reached combined primary endpoints during follow-up, and 171 (12.9\%) patients reached ESRD. Patients were further divided based on crescent and global glomerulosclerosis. Patients with crescents and global glomerulosclerosis were divided into $\mathrm{C} 0 / 1 / 2$ and $\mathrm{G} 0 / 1 / 2$ groups. Patients with higher portion of crescents and global glomerulosclerosis seem to have severer disease with lower eGFR, serum albumin and higher proteinuria, and pathological changes (Table 1 and 2)

\section{Treatment response}

Treatment responses were assessed in relation to pathological lesions (Table 3 and 4). CR rate was significantly lower in patients in C2 group (C0 60.3\%, C1 62.6\% and C2 $42.3 \%$ ), however ESRD rate was remarkably higher in patients in C2 group (C0 15.4\%, C1 $13.6 \%, \mathrm{C} 235.9 \%$ ). It was found that patients with crescents were more likely to receive immunosuppressive treatment than those without crescents (C0 54.1\%, C1 77.0\%, C2 88.5\%). Moreover, immunosuppressant treatment was apparently associated with, higher CR and PR rate in patients in crescent groups. In our study cohort, higher portion of globe glomerulosclerosis was associated with lower CR and PR rate and higher ESRD (G0 4.3\%, G1 32.0\%, G2 75.2\%) rate. The percentages of patients receiving immunosuppressant were similar in different G groups (G0 59.3\%, G1 66.9\%, G2 55.6\%). Only 1 patient died during follow-up due to severe pulmonary infection. 


\section{Kidney Blood Pressure Research}

Table 1. Baseline clinicopathological characteristics of IgAN patients in different crescent scores. Data presented as number (percentage) or mean \pm SD or median (frst-third interquartile range) eGFR, estimated glomerular filtration rate; NS, nephrotic syndrome; RBC, red blood cell; Scr, serum creatinine. ${ }^{*} \mathrm{P}<0.05$ compared to $\mathrm{C} 0,{ }^{* *} \mathrm{P}<0.05$ compared to $\mathrm{C} 0$ and $\mathrm{C} 1$

\begin{tabular}{|c|c|c|c|c|c|}
\hline Variables & $\begin{array}{c}\text { All } \\
n=1328\end{array}$ & $\begin{array}{c}0 \\
\mathrm{n}=993\end{array}$ & $\begin{array}{c}\text { Crescent } \\
1 \\
n=257\end{array}$ & $\begin{array}{c}2 \\
\mathrm{n}=78\end{array}$ & $\mathrm{P}$ \\
\hline Gender & & & & & 0.956 \\
\hline Male & $605(45.6)$ & $454(45.7)$ & $115(44.7)$ & $36(46.2)$ & \\
\hline Female & $723(54.4)$ & $559(54.3)$ & $142(55.3)$ & $42(53.8)$ & \\
\hline Age, year & $34.2 \pm 11.2$ & $34.6 \pm 11.3$ & $33.7 \pm 10.6$ & $31.2 \pm 11.3^{*}$ & 0.025 \\
\hline Disease duration, month & $15.0 \pm 24.1$ & $16.0 \pm 25.1$ & $12.7 \pm 22.0$ & $9.5 \pm 15.8^{*}$ & 0.017 \\
\hline eGFR, $\left(\mathrm{ml} / \mathrm{min}\right.$ per $\left.1.73 \mathrm{~m}^{2}\right)$ & $84.0 \pm 34.9$ & $86.2 \pm 34.7$ & $78.8 \pm 32.9^{*}$ & $72.7 \pm 40.1^{*}$ & $<0.001$ \\
\hline CKD stage & & & & & $<0.001$ \\
\hline 1 & $620(46.7)$ & $490(49.3)$ & $107(41.6)$ & $23(29.5)$ & \\
\hline 2 & $329(24.8)$ & $242(24.4)$ & $65(25.3)$ & $22(28.2)$ & \\
\hline 3 & $287(21.6)$ & $197(19.8)$ & $66(25.7)$ & $24(30.8)$ & \\
\hline 4 & $92(6.9)$ & $64(6.4)$ & $19(7.4)$ & $9(11.5)$ & \\
\hline Hypertension & $494(37.2)$ & $367(37.0)$ & $96(37.4)$ & $31(39.7)$ & 0.886 \\
\hline \multicolumn{6}{|l|}{ Oxford classification } \\
\hline M1 & $1043(78.5)$ & $747(75.2)$ & $220(85.6)$ & $76(97.4)$ & $<0.001$ \\
\hline E1 & $64(4.8)$ & $12(1.2)$ & $25(9.7)$ & $27(34.6)$ & $<0.001$ \\
\hline S1 & $675(50.8)$ & $473(47.6)$ & $155(60.3)$ & $47(60.3)$ & $<0.001$ \\
\hline $\mathrm{T} 1 / 2$ & $328(24.7)$ & $234(23.6)$ & $68(26.5)$ & $26(33.3)$ & 0.133 \\
\hline Proteinuria, g/24h & $2.8 \pm 3.0$ & $2.6 \pm 3.0$ & $3.1 \pm 3.1^{*}$ & $4.4 \pm 2.9^{* *}$ & $<0.001$ \\
\hline Albumin, $\mathrm{g} / \mathrm{L}$ & $37.7 \pm 11.8$ & $38.0 \pm 13.0$ & $37.5 \pm 6.5$ & $33.0 \pm 7.3^{* *}$ & 0.001 \\
\hline NS & $223(16.9)$ & $156(15.7)$ & $40(15.6)$ & 27 (34.6) & $<0.001$ \\
\hline Scr, mg/dL & $1.20 \pm 0.64$ & $1.16 \pm 0.62$ & $1.29 \pm 0.65^{*}$ & $1.47 \pm 0.82^{* *}$ & $<0.001$ \\
\hline Immunosuppression & $804(60.5)$ & $537(54.1)$ & $198(77.0)$ & $69(88.5)$ & $<0.001$ \\
\hline
\end{tabular}

Table 2. Baseline clinicopathological characteristics of IgAN patients in different glomerulosclerosis scores. Data presented as number (percentage) or mean \pm SD or median (frst-third interquartile range)

\begin{tabular}{|c|c|c|c|c|c|}
\hline \multirow[b]{2}{*}{ Variables } & \multirow[b]{2}{*}{$\begin{array}{c}\text { All } \\
\mathrm{n}=1328\end{array}$} & \multicolumn{3}{|c|}{ Glomerulosclerosis } & \multirow[b]{2}{*}{$\mathrm{P}$} \\
\hline & & $\begin{array}{c}0 \\
\mathrm{n}=936\end{array}$ & $\begin{array}{c}1 \\
\mathrm{n}=275\end{array}$ & $\begin{array}{c}2 \\
\mathrm{n}=117\end{array}$ & \\
\hline Gender & & & & & 0.136 \\
\hline Male & $605(45.6)$ & $414(44.2)$ & $128(46.5)$ & $63(54.3)$ & \\
\hline Female & $723(54.4)$ & $522(55.8)$ & $147(53.5)$ & $54(46.2)$ & \\
\hline Age, year & $34.2 \pm 11.2$ & $33.6 \pm 11.6$ & $36.1 \pm 9.5^{*}$ & $34.7 \pm 11.2$ & 0.005 \\
\hline Disease duration, month & $15.0 \pm 24.1$ & $13.6 \pm 22.6$ & $19.1 \pm 27.9^{*}$ & $16.4 \pm 25.3$ & 0.003 \\
\hline eGFR, $\left(\mathrm{ml} / \mathrm{min}\right.$ per $\left.1.73 \mathrm{~m}^{2}\right)$ & $84.0 \pm 34.9$ & $96.0 \pm 30.2$ & $62.0 \pm 28.3^{*}$ & $39.8 \pm 20.4^{* *}$ & $<0.001$ \\
\hline CKD stage & & & & & $<0.001$ \\
\hline 1 & $620(46.7)$ & $567(60.6)$ & 49 (17.8) & $4(3.4)$ & \\
\hline 2 & $329(24.8)$ & $239(25.5)$ & $76(27.6)$ & $14(12.0)$ & \\
\hline 3 & $287(21.6)$ & $112(12.0)$ & $118(42.9)$ & $57(48.7)$ & \\
\hline 4 & $92(6.9)$ & $18(1.9)$ & $32(11.6)$ & $42(35.9)$ & \\
\hline Hypertension & $494(37.2)$ & $258(27.6)$ & $149(54.2)$ & $96(75.6)$ & $<0.001$ \\
\hline \multicolumn{6}{|l|}{ Oxford classification } \\
\hline M1 & $1043(78.5)$ & $688(73.5)$ & $244(88.7)$ & $111(94.9)$ & $<0.001$ \\
\hline E1 & $64(4.8)$ & $52(5.6)$ & $10(3.6)$ & $2(1.7)$ & 0.074 \\
\hline $\mathrm{S} 1$ & $675(50.8)$ & $401(42.8)$ & $197(71.6)$ & $77(65.8)$ & $<0.001$ \\
\hline $\mathrm{T} 1 / 2$ & $328(24.7)$ & $76(8.1)$ & $145(52.7)$ & $107(91.5)$ & $<0.001$ \\
\hline Proteinuria, g/24h & $2.8 \pm 3.0$ & $2.7 \pm 3.3$ & $2.8 \pm 2.2$ & $3.6 \pm 2.4^{* *}$ & 0.009 \\
\hline Albumin, $\mathrm{g} / \mathrm{L}$ & $37.7 \pm 11.8$ & $37.8 \pm 13.5$ & $37.8 \pm 5.9$ & $35.6 \pm 6.2$ & 0.149 \\
\hline NS & $223(16.9)$ & $164(17.5)$ & $40(14.7)$ & 19 (16.5) & 0.540 \\
\hline Scr, mg/dL & $1.20 \pm 0.64$ & $0.98 \pm 0.43$ & $1.51 \pm 0.68^{*}$ & $2.19 \pm 0.76^{* *}$ & $<0.001$ \\
\hline Immunosuppression & $804(60.5)$ & $555(59.3)$ & $184(66.9)$ & $65(55.6)$ & 0.037 \\
\hline
\end{tabular}




\section{Kidney Blood Pressure Research}

Peng et al.: Crescents and Global Glomerulosclerosis in IgA Nephropathy

Table 3. Treatment responses in IgAN patients with different crescent scores. IT, immunosuppressive therapy; SC, supportive care; CR, complete remission; PR, partial remission; NR, no response; ESRD, end stage renal disease

\begin{tabular}{|c|c|c|c|c|c|c|c|c|c|}
\hline Response & & $\mathrm{C} 0$ & & & C1 & & & $\mathrm{C} 2$ & \\
\hline & $\begin{array}{c}\text { All } \\
\mathrm{n}=993\end{array}$ & $\begin{array}{c}\text { IT } \\
\mathrm{n}=537(54.1 \%)\end{array}$ & $\begin{array}{c}\mathrm{SC} \\
\mathrm{n}=456(45.9 \%)\end{array}$ & $\begin{array}{c}\text { All } \\
\mathrm{n}=257\end{array}$ & $\begin{array}{c}\text { IT } \\
\mathrm{n}=198(77.0 \%)\end{array}$ & $\begin{array}{c}\mathrm{SC} \\
\mathrm{n}=59(23.0 \%)\end{array}$ & $\begin{array}{c}\text { All } \\
\mathrm{n}=78\end{array}$ & $\begin{array}{c}\text { IT } \\
n=69(88.5 \%)\end{array}$ & $\begin{array}{c}\text { SC } \\
n=9(11.5 \%)\end{array}$ \\
\hline CR & $\begin{array}{c}599 \\
(60.3 \%)\end{array}$ & $347(64.6 \%)$ & $252(55.3 \%)$ & $161(62.6 \%)$ & $133(67.2 \%)$ & $28(47.5 \%)$ & $33(42.3 \%)$ & $33(47.8 \%)$ & $0(0.0 \%)$ \\
\hline PR & $\begin{array}{c}105 \\
(10.6 \%)\end{array}$ & $71(13.2 \%)$ & $34(7.4 \%)$ & $27(10.5 \%)$ & $24(12.1 \%)$ & $3(5.1 \%)$ & $10(12.8 \%)$ & $9(13.0 \%)$ & $1(11.1 \%)$ \\
\hline NR & $\begin{array}{c}135 \\
(13.6 \%)\end{array}$ & $47(8.8 \%)$ & $88(19.3 \%)$ & $34(13.2 \%)$ & $16(8.1 \%)$ & $18(30.5 \%)$ & $7(9.0 \%)$ & $4(5.8 \%)$ & $3(33.3 \%)$ \\
\hline ESRD & $\begin{array}{c}153 \\
(15.4 \%)\end{array}$ & $71(13.2 \%)$ & $82(18.0 \%)$ & $35(13.6 \%)$ & $25(12.6 \%)$ & $10(16.9 \%)$ & $28(35.9 \%)$ & $23(33.3 \%)$ & $5(55.6 \%)$ \\
\hline
\end{tabular}

Table 4. Treatment responses in IgAN patients with different glomerulosclerosis scores. IT, immunosuppressive therapy; $\mathrm{SC}$, supportive care; $\mathrm{CR}$, complete remission; PR, partial remission; NR, no response; ESRD, end stage renal disease

\begin{tabular}{|c|c|c|c|c|c|c|c|c|c|}
\hline Response & & G0 & & & G1 & & & G2 & \\
\hline & All & IT & $\mathrm{SC}$ & All & IT & $\mathrm{SC}$ & All & IT & SC \\
\hline & $\mathrm{n}=936$ & $\mathrm{n}=555(59.3 \%)$ & $\mathrm{n}=381(40.7 \%)$ & $\mathrm{n}=275$ & $\mathrm{n}=184(66.9 \%)$ & $\mathrm{n}=91(33.1 \%)$ & $\mathrm{n}=117$ & $\mathrm{n}=65(55.6 \%)$ & $n=52(44.4 \%)$ \\
\hline CR & $675(72.1 \%)$ & $419(75.5 \%)$ & $256(67.2 \%)$ & $107(38.9 \%)$ & $84(45.6 \%)$ & $23(25.3 \%)$ & $11(9.4 \%)$ & $10(15.4 \%)$ & $1(1.9 \%)$ \\
\hline PR & $99(10.6 \%)$ & $66(11.9 \%)$ & $33(8.7 \%)$ & $37(13.5 \%)$ & $32(17.4 \%)$ & $5(5.5 \%)$ & $6(5.1 \%)$ & $6(9.2 \%)$ & $0(0.0 \%)$ \\
\hline NR & $121(12.9 \%)$ & $39(7.0 \%)$ & $82(21.5 \%)$ & $43(15.6 \%)$ & $20(10.9 \%)$ & $23(25.3 \%)$ & $12(10.3 \%)$ & $8(12.3 \%)$ & $4(7.7 \%)$ \\
\hline ESRD & $40(4.3 \%)$ & $30(5.4 \%)$ & $10(2.6 \%)$ & $88(32.0 \%)$ & $48(26.1 \%)$ & $40(43.9 \%)$ & $88(75.2 \%)$ & $41(63.1 \%)$ & $47(90.4 \%)$ \\
\hline
\end{tabular}

\section{Predictive assessment of clinical outcomes}

In the present study, 221 patients $(16.6 \%)$ reached combined primary end point (C0: 164 cases, C1: 31 cases, C2: 26 cases, and G0: 44 cases, G1: 87 cases, G2: 90 cases). KaplanMeier analysis showed that $\mathrm{C}$ and $\mathrm{G}$ were significantly associated with renal outcome (log rank: $\mathrm{C} 1$ vs $\mathrm{C} 0, \mathrm{P}=0.200, \mathrm{C} 2$ vs $\mathrm{C} 0, \mathrm{P}<0.001, \mathrm{C} 2$ vs $\mathrm{C} 1, \mathrm{P}<0.001$; $\mathrm{G} 1$ vs $\mathrm{G} 0, \mathrm{P}<0.001, \mathrm{G} 2$ vs G0, $\mathrm{P}<0.001$, G2 vs G1, $\mathrm{P}<0.001$ ) (Fig. 1 and 2). The correlation between clinicopathological parameters and renal outcome were also analyzed in COX regression model (Table 5). In univariate analysis, all variables except age and disease duration prior to renal biopsy were associated with an increased risk for the combined endpoint. In multivariate analysis, independent predictors of poor renal survival included T1/2, C2, G1, G2, serum creatinine levels, arterial hypertension, and nephrotic syndrome at the time of biopsy.

\section{Effects of $C$ and $G$ on discrimination of survival models}

ROC curves were used to further investigate the predictive power of crescents and global glomerulosclerosis in evaluating 5-year renal survival. Model 1 in Fig. 3 comprised the statistically significant variables in univariate analysis in Table 5. The AUC value of model 1 was 0.9234 . When G was removed from the model, the AUC value was 0.9020 . And when $\mathrm{C}$ and $\mathrm{G}$ were both removed, the AUC value was 0.9001 . These results indicate that $\mathrm{C}$ and $\mathrm{G}$ scores contribute to improved discrimination of the survival model.

\section{Discussion}

In this study, we found that global glomerulosclerosis ( $>25 \%$ of glomeruli) and crescents ( $>25 \%$ of glomeruli) were independently associated with renal survival of IgAN patients. We observed a more than two-fold increased risk (C2 vs C0 2.366, G1 vs G0 2.552, G2 vs G0 4.678) of poor renal outcome ( $50 \%$ reduction of eGFR and ESRD), suggesting high prognostic significance of crescent and glomerulosclerosis in renal biopsy.

Although the predictive value of crescents was not confirmed in the original Oxford study (excluding individuals with severe renal insufficiency) [9], new studies found that crescents was strong predictors of unfavorable prognosis of IgAN [10]. Therefore, the Oxford classification was revised to add the crescent score [5]. It is important to note that this only applies to well defined cellular or fibrocellular crescents and not to fibrous crescents. In the 


\section{Kidney Blood Pressure Research}

Fig. 1. Kaplan-Meier analysis for the probability of primary endpoint in patients with different $\mathrm{C}$ scores.

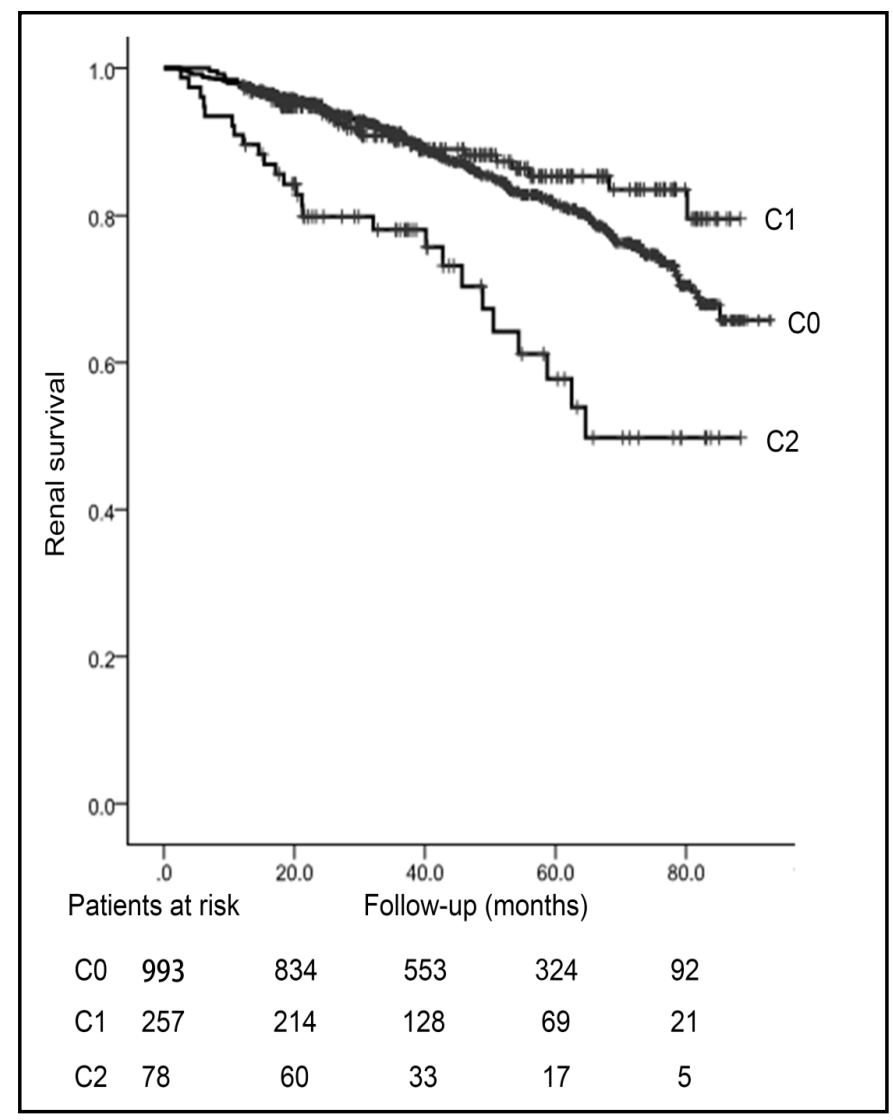

Fig. 2. Kaplan-Meier analysis for the probability of primary endpoint in patients with different G scores.

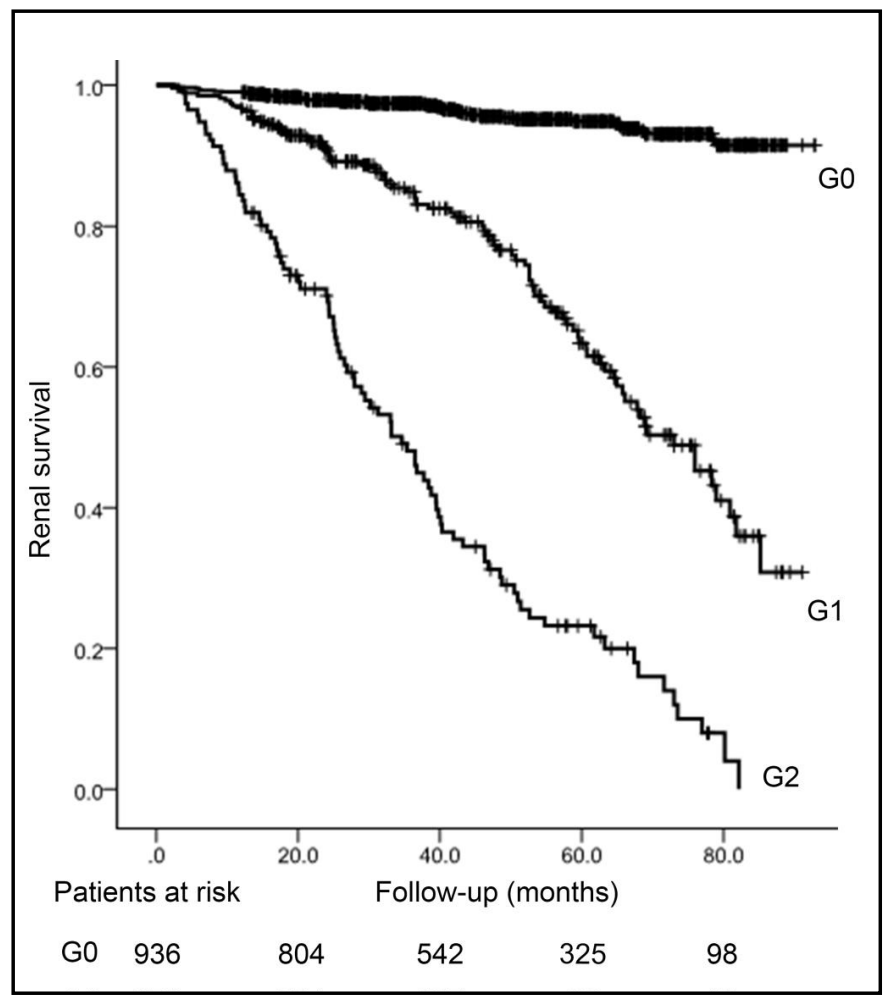




\section{Kidney Blood Pressure Research}

current study, we found that C2 (HR 2.366; 95\% CI 1.434 to 3.904) was a predictor of poor renal survival. Patients in C2 group experienced a lower CR rate and higher ESRD rate. These results suggested that presence of crescents in more than $25 \%$ of glomeruli indicated aggressive disease progression and required early initiation of steroids and immunosuppressant. Nevertheless, the 2012 KDIGO Guidelines recommended immunosuppressive therapy only for crescentic IgAN, which defined as IgAN with crescents in more than $50 \%$ of glomeruli in the renal biopsy [11]. This may compromise the application of adequate treatment and lead to poor renal survival in IgAN patients with crescents. In the current cohort, we found that more patients in C2 group received immunosuppressant than patients in $\mathrm{C} 1$ and $\mathrm{C} 0$ groups. Moreover, aggressive treatment contain immunosuppressant could effectively improve the renal outcome of IgAN patients (especially patients with crescents), which is similar to several other studies [12] [13]. Inconsistent with previous reports [10], C1 did not independently predict renal outcome in our cohort, and treatment responses were similar in patients in C1 and C0 groups. Because patients with crescent in a least 1 glomerulus was included in $\mathrm{C} 1$ group, the exact number and portion of glomeruli with crescents were relatively low in our cohort. Moreover, patients in $\mathrm{C} 1$ group received considerably aggressive treatment (contained corticosteroid and immunosuppressant) than patients in $\mathrm{C} 0$ group. These may be the reason why no significant difference was observed in renal prognosis between $\mathrm{C} 1$ and $\mathrm{C} 0$ groups in the current cohort. However, these findings need to be validated in further study.
Table 5. Variable associated with renal survival in the cox analysis. HTN, hypertension; NS, nephrotic syndrome; Scr, serum crestinine

\begin{tabular}{lccc}
\hline \multirow{2}{*}{ Variable } & \multicolumn{3}{c}{ Renal survival } \\
& $\begin{array}{c}\text { Univariate analysis } \\
\text { P-value }\end{array}$ & Multivariate analysis \\
& 0.006 & HR(95\% CI) & P-value \\
\hline Gender & & (Referent) & \\
Male & & $1.216(0.910-1.624)$ & 0.186 \\
Female & 0.154 & & \\
Age (per year) & 0.054 & & \\
Duration (per month) & & & \\
Oxford classification & $<0.001$ & $2.131(0.929-4.891)$ & 0.074 \\
$\quad$ M1 vs M0 & 0.006 & $1.886(1.013-3.513)$ & 0.045 \\
$\quad$ E1 vs E0 & $<0.001$ & $1.193(0.874-1.628)$ & 0.267 \\
\multicolumn{1}{l}{ S1 vs S0 } & $<0.001$ & $2.582(1.650-4.010)$ & $<0.001$ \\
$\quad$ T1/2 vs T0 & 0.231 & $0.764(0.508-1.148)$ & 0.196 \\
C1 vs C0 & $<0.001$ & $2.366(1.434-3.904)$ & 0.001 \\
C2 vs C0 & $<0.001$ & $2.552(1.630-3.996)$ & $<0.001$ \\
G1 vs G0 & $<0.001$ & $4.678(2.758-7.936)$ & $<0.001$ \\
G2 vs G0 & $<0.001$ & $2.210(1.577-3.097)$ & $<0.001$ \\
HTN & $<0.001$ & $2.178(1.548-3.065)$ & 0.002 \\
NS & $<0.001$ & $2.184(1.772-2.691)$ & $<0.001$ \\
Scr (per mg/dL) & $<0.001$ & $0.577(0.426-0.780)$ & $<0.001$ \\
Immunosuppression & & & \\
\hline
\end{tabular}

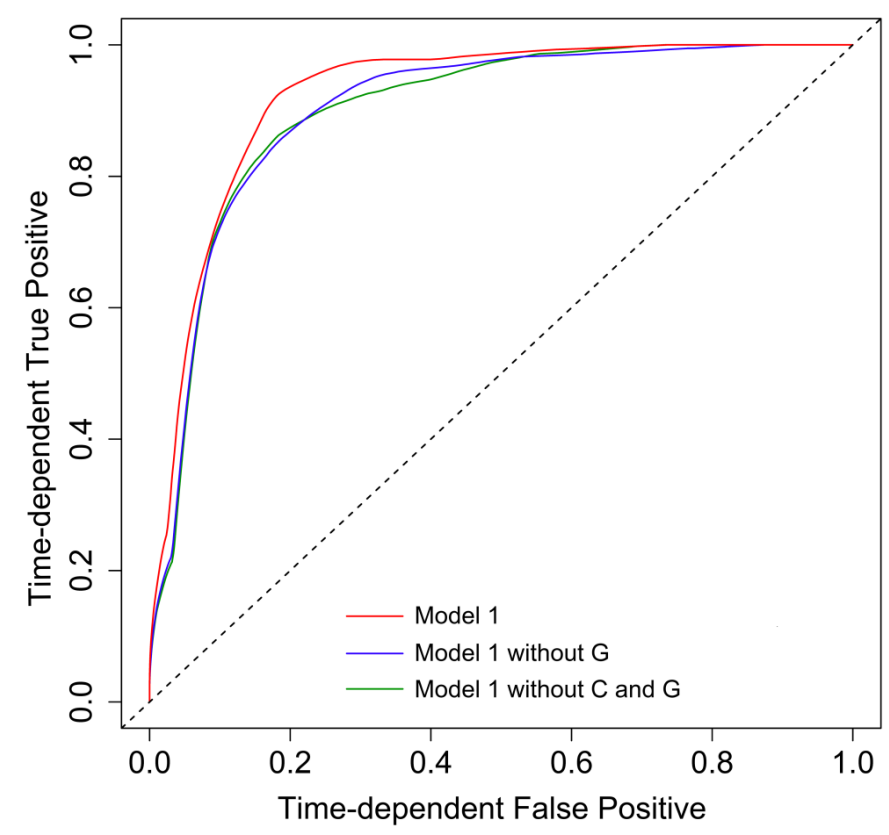

Fig. 3. ROC curves for each model
Peng et al.: Crescents and Global Glomerulosclerosis in IgA Nephropathy 


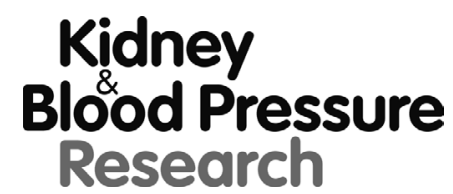

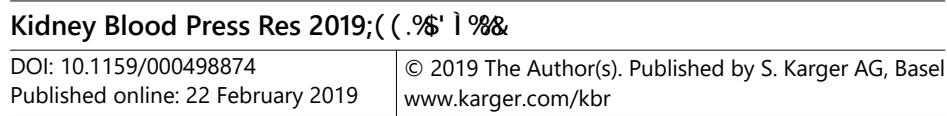

Peng et al.: Crescents and Global Glomerulosclerosis in IgA Nephropathy

It is well accepted that chronic pathological changes such as glomerular sclerosis, tubular atrophy and interstitial fibrosis are strongly associated with poor long term renal survival of kidney disease. However, previous studies only emphasized the association between tubular atrophy and interstitial fibrosis (T) and renal survival [14]. Several investigators found that global glomerulosclerosis was an independent risk factor for ESRD of IgAN [15], but no further study was performed. Although a correlation between global glomerulosclerosis and tubulointerstitial atrophy and fibrosis has been reported previously [16], in certain conditions tubulointerstitial changes may not in consistent with glomerulosclerosis. This is especially true in patients with a history of hypertension, analgesic use, or traditional Chinese medicine exposure. Considering that global glomerulosclerosis is an indicator of advanced irreversible lesion and it also suggests poor response to treatment, we thought that global glomerulosclerosis may also be a predictor of poor renal outcome of IgAN. In this study we found that higher proportion of glomeruli with global sclerosis were significantly associated with poor renal outcome (G1: HR 2.552; 95\% CI 1.630 to 3.996 and G2: HR 4.678; 95\% CI 2.758 to 7.936 ). It should further be noted that combination of $\mathrm{G}$ and $\mathrm{C}$ score could improve discrimination for the prediction of renal survival (Fig. 3). Therefore, it is reasonable to add global glomerulosclerosis $(G)$ in the pathology score system of IgAN patients.

In this study we found that treatment responses in patients of G2 group were poor, and $90 \%$ patients reached primary end point during follow up in spite of the treatment. Previously, it was reported that glomerular sclerosis $(>40 \%)$ was a predictor of poor renal outcome [17], while our study identified that $>25 \%$ glomerulosclerosis was strongly correlated with renal survival. These results suggested that aggressive treatment (corticosteroids and immunosuppressant) may not be appropriate in patients with high portion of global glomerulosclerosis ( $>25 \%)$. However, additional studies are required to confirm our findings.

Results of our study suggested that both pathological change and clinical character are closely related to the disease prognosis. Patients with active proliferative lesions (cellular or fibrocellular crescents), should receive more aggressive treatment such as steroids and/or immunosuppressant as these changes are potentially reversible. Although STOP Trial showed no significant effect of adding immunosuppression to supportive care, pathological changes were not considered [18]. It was reported that mycophenolate mofetil and prednisone or prednisone alone could achieve good treatment response in IgAN patients with active proliferative lesions [19]. However, in patients with apparent chronic pathological changes (G2), corticosteroids and immunosuppressant may not be beneficial.

Our novel findings should be interpreted within the context of the study's limitations. First, this is a retrospective study in a single center in China. It is not verified whether our participants have distinctive demographic or ethnic backgrounds. Second, the therapeutic interventions were varied as were specific immunosuppressive regimens, which may impair data interpretation. Besides, the immunosuppression related complications were not elucidated in this study. Third, 5-year follow-up was relatively short, and IgAN is known to progress slowly. Patient follow-ups should be continuous and extended.

\section{Conclusion}

Cellular and fibrocellular crescents and global glomerulosclerosis were independently associated with unfavorable prognosis of IgA nephropathy at 5 years, even after adjusting for clinical factors and MEST pathological parameters. Results of the current study strongly suggest that pathological activity should be included when determining treatment strategy for IgAN patients. 


\section{Kidney \\ Blood Pressure Research}

Peng et al.: Crescents and Global Glomerulosclerosis in IgA Nephropathy

\section{Acknowledgements}

This study is partly supported by NSFC 81270793, and Scientific fund of Health Commission of Sichuan Province 17ZD013. This study complies with the principles of the Helsinki Declaration and was approved by The Ethics Committee of West China Hospital of Sichuan University.

\section{Disclosure Statement}

The authors declared no potential conflicts of interest with respect to the research, authorship, and/or publication of this article.

\section{References}

1 Kim JK, Kim JH, Lee SC, Kang EW, Chang TI, Moon SJ, Yoon SY, Yoo TH, Kang SW, Choi KH, Han DS, Kie JH, Lim BJ, Jeong HJ, Han SH: Clinical features and outcomes of IgA nephropathy with nephrotic syndrome. Clin J Am Soc Nephrol 2012;7:427-436.

-2 Cattran DC, Coppo R, Cook HT, Feehally J, Roberts IS, Troyanov S, Alpers CE, Amore A, Barratt J, Berthoux F, Bonsib S, Bruijn JA, D’Agati V, D’Amico G, Emancipator S, Emma F, Ferrario F, Fervenza FC, Florquin S, Fogo A, et al.: The Oxford classification of IgA nephropathy: rationale, clinicopathological correlations, and classification. Kidney Int 2009;76:534-545.

-3 Herzenberg AM, Fogo AB, Reich HN, Troyanov S, Bavbek N, Massat AE, Hunley TE, Hladunewich MA, Julian BA, Fervenza FC, Cattran DC: Validation of the Oxford classification of IgA nephropathy. Kidney Int 2011;80:310-317.

$>4$ Lv J, Shi S, Xu D, Zhang H, Troyanov S, Cattran DC, Wang H: Evaluation of the Oxford Classification of IgA nephropathy: a systematic review and meta-analysis. Am J Kidney Dis 2013;62:891-899.

-5 Trimarchi H, Barratt J, Cattran DC, Cook HT, Coppo R, Haas M, Liu ZH, Roberts IS, Yuzawa Y, Zhang H, Feehally J: Oxford Classification of IgA nephropathy 2016: an update from the IgA Nephropathy Classification Working Group. Kidney Int 2017;91:1014-1021.

6 Coppo R: Corticosteroids in IgA Nephropathy: Lessons from Recent Studies. J Am Soc Nephrol 2017;28:2533.

7 Sethi S, Haas M, Markowitz GS, D’Agati VD, Rennke HG, Jennette JC, Bajema IM, Alpers CE, Chang A, Cornell LD, Cosio FG, Fogo AB, Glassock RJ, Hariharan S, Kambham N, Lager DJ, Leung N, Mengel M, Nath KA, Roberts IS, et al.: Mayo Clinic/Renal Pathology Society Consensus Report on Pathologic Classification, Diagnosis, and Reporting of GN. J Am Soc Nephrol 2016;27:1278-1287.

-8 Heagerty PJ, Lumley T, Pepe MS: Time-dependent ROC curves for censored survival data and a diagnostic marker. Biometrics 2000;56:337-344.

>9 Coppo R, Troyanov S, Bellur S, Cattran D, Cook HT, Feehally J, Roberts IS, Morando L, Camilla R, Tesar V, Lunberg S, Gesualdo L, Emma F, Rollino C, Amore A, Praga M, Feriozzi S, Segoloni G, Pani A, Cancarini G, et al.: Validation of the Oxford classification of IgA nephropathy in cohorts with different presentations and treatments. Kidney Int 2014;86:828-836.

10 Haas M, Verhave JC, Liu ZH, Alpers CE, Barratt J, Becker JU, Cattran D, Cook HT, Coppo R, Feehally J, Pani A, Perkowska-Ptasinska A, Roberts IS, Soares MF, Trimarchi H, Wang S, Yuzawa Y, Zhang H, Troyanov S, Katafuchi R: A Multicenter Study of the Predictive Value of Crescents in IgA Nephropathy. J Am Soc Nephrol 2017;28:691-701.

11 Beck L, Bomback AS, Choi MJ, Holzman LB, Langford C, Mariani LH, Somers MJ, Trachtman H, Waldman M: KDOQI US commentary on the 2012 KDIGO clinical practice guideline for glomerulonephritis. Am J Kidney Dis 2013;62:403-441.

12 Zhang W, Zhou Q Hong L, Chen W, Yang S, Yang Q, Yu X: Clinical outcomes of IgA nephropathy patients with different proportions of crescents. Medicine 2017;96:e6190. 


\section{Kidney \\ Blood Pressure Research}

13 Tan L, Tang Y, Peng W, Mathew BS, Qin W: Combined Immunosuppressive Treatment May Improve ShortTerm Renal Outcomes in Chinese Patients with Advanced IgA Nephropathy. Kidney Blood Press Res 2018;43:1333-1343.

14 El Karoui K, Hill GS, Karras A, Moulonguet L, Caudwell V, Loupy A, Bruneval P, Jacquot C, Nochy D: Focal segmental glomerulosclerosis plays a major role in the progression of IgA nephropathy. II. Light microscopic and clinical studies. Kidney Int 2011;79:643-654.

-15 Woo KT, Lim CC, Foo MW, Loh HL, Jin AZ, Chin YM, Choo JC, Tan PH, Chow KY, Choong LH, Tan HK, Wong KS, Chan CM: 30-year follow-up study of IgA nephritis in a Southeast Asian population: an evaluation of the Oxford histological classification. Clin Nephrol 2016;86:270-278.

-16 Kawamura T, Joh K, Okonogi H, Koike K, Utsunomiya Y, Miyazaki Y, Matsushima M, Yoshimura M, Horikoshi S, Suzuki Y, Furusu A, Yasuda T, Shirai S, Shibata T, Endoh M, Hattori M, Katafuchi R, Hashiguchi A, Kimura $\mathrm{K}$, Matsuo S, et al.: A histologic classification of IgA nephropathy for predicting long-term prognosis: emphasis on end-stage renal disease. J Nephrol 2013;26:350-357.

17 Walsh M, Sar A, Lee D, Yilmaz S, Benediktsson H, Manns B, Hemmelgarn B: Histopathologic features aid in predicting risk for progression of IgA nephropathy. Clin J Am Soc Nephrol 2010;5:425-430.

18 Rauen T, Eitner F, Fitzner C, Sommerer C, Zeier M, Otte B, Panzer U, Peters H, Benck U, Mertens PR, Kuhlmann U, Witzke O, Gross O, Vielhauer V, Mann JF, Hilgers RD, Floege J: Intensive Supportive Care plus Immunosuppression in IgA Nephropathy. N Engl J Med 2015;373:2225-2236.

19 Hou JH, Le WB, Chen N, Wang WM, Liu ZS, Liu D, Chen JH, Tian J, Fu P, Hu ZX, Zeng CH, Liang SS, Zhou ML, Zhang HT, Liu ZH: Mycophenolate Mofetil Combined With Prednisone Versus Full-Dose Prednisone in IgA Nephropathy With Active Proliferative Lesions: A Randomized Controlled Trial. Am J Kidney Dis 2017;69:788-795. 